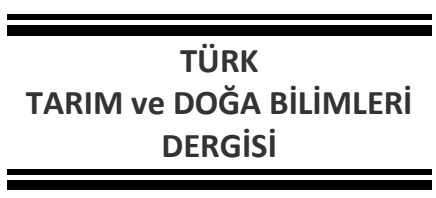

\title{
Dilkanatanın (Galium aparine L.) Çimlenme Biyolojisi ve Bazı Herbisitlere Tepkisi
}

\author{
Nurcan BÜYÜKKURT' ${ }^{*}$, Ahmet ULUDAĞ ${ }^{2}$ \\ ${ }^{1}$ Düzce Üniversitesi, Ziraat ve Doğa Bilimleri Fakültesi, Düzce, Türkiye \\ ${ }^{2}$ Çanakkale Onsekiz Mart Üniversitesi, Ziraat Fakültesi, Çanakkale, Türkiye \\ *Sorumlu yazar: nurcan.buyukkurt@yahoo.com
}

Geliş Tarihi: 18.06.2019 Düzeltme Geliş Tarihi: 30.06.2019 Kabul Tarihi: 14.07.2019

Özet

Çok sayıda türü olan Galium cinsinden dilkanatan (Galium aparine) birçok ülkede ve kültür bitkisinde yabancıot olarak önem arzetmektedir. Özellikle ülkemizde son yirmi yılda herbisitlere dayanıklılık vakalarının kaydedilmeye başlaması, bu rekabetçi yabancıotu daha fazla gündeme getirmektedir. Sakarya ilinde de çiftçiler herbisitlerin bu yabancıotu kontrol etmede yetersiz kalmaya başladığını bildirmektedirler. Bu bağlamda dilkanatanın çimlenme biyolojisini ve herbisitlere tepkisini belirlemek amacıyla bu çalışma yapılmıştır. Sakarya ilinden dayanıklılık şüphesiyle alınan tohumlarla yapılan çimlendirme denemesinde $20^{\circ} \mathrm{C}^{\prime}$ de hiç çimlenme olmazken, $10^{\circ} \mathrm{C}^{\prime}$ de $\% 93,5$ çimlenme kaydedilmiştir. Yavaş seyretmesine ve geç çimlenmeye başlamasına rağmen $4^{\circ} \mathrm{C}^{\prime}$ de çimlenme 21 nci günde $\% 71,5^{\prime} \mathrm{e}$ ulaşmıştır ve bu değer $15^{\circ} \mathrm{C}^{\prime}$ deki çimlenme oranının iki katından fazladır. Sakarya populasyonu ile tarla dışından toplanan Düzce populasyonu petri denemelerinde herbisit formulasyonlarına (tribenuron+tifensülfüron, mezosülfüron+iyodosülfüron+mefenpir, propoksikarbazon+mezosülfüron+mefenpir, klorsülfüron ve 2,4-D amin) karşı denenmiş ve Sakarya populasyonunda özellikle düşük dozlarda daha fazla kök uzaması tespit edilmiştir, bu durum Sakarya populasyonunda etki düşüklüğü şüphesini doğrulayan bir veridir. Mezosülfüron+iyodosülfüron+mefenpir ile saksıda yapılan dozatepki denemesi sonucunda Sakarya tarla populasyonu, Düzce tarla dışı alan popülasyonuna göre $\mathrm{ED}_{50}$ seviyesinde 1,36 kat ve $\mathrm{ED}_{90}$ seviyesinde 2,53 kat daha dayanıklı bulunmuştur. Bu sonuç tam bir dayanıklılık olduğunu göstermese de herbisitin etkisindeki azalmanın bir ifadesidir. Çimlenme özellikleri ve herbisitlerin etkilerindeki azalma itibariyle dilkanatanın daha fazla mesele olabileceği bu sebeple daha fazla ve ayrıntılı araştırmalara ihtiyaç olduğu kanaatine varılmıştır.

Anahtar kelimeler: 2,4-D amin, herbisitlere dayanıklılık, klorsülfüron, mezosülfüron+iyodo- sülfüron+mefenpir, propoksikarbazon+mezosülfüron+mefenpir, tribenuron+tifensülfüron.

\section{Germination Biology of Catchweed Bedstraw (Galium aparine L.) and Its Response to Some Herbicides}

\footnotetext{
Abstract

Catchweed bedstraw (Galium aparine L.) that is one of the many species which belong to genus Galium is among important weeds of many crops in many countries. It became more prominent especially in the last decade due to herbicide resistance cases as well as its competitive ability. Farmers from the Sakarya Province of Turkey have already complained about herbicides that has become inefficient in catchweed bedstraw control. The study on germination biology of catchweed bedstraw and its response to herbicides has been carried out under this context. There was no germination at $20^{\circ} \mathrm{C}$ while $93.5 \%$ was recorded at $10^{\circ} \mathrm{C}$ for the seeds of Sakarya population which was suspected herbicide resistant. Although it was started late and occurred slowly, the germination reached $71.5 \%$ at $4^{\circ} \mathrm{C}$, which is more than twice of germination at $15^{\circ} \mathrm{C}$ at $21^{\text {st }}$ day. Both populations from Sakarya and Düzce Provinces,
} 
of which seeds of latter were collected from non-agricultural areas were undergone dose-response experiments in petri dishes for five different herbicide formulations namely; mesosulfuron+iodosulfuron, propoxycarbazone+mesosulfuron, chlorsulfuron, tribenuron+thifensulfuron and 2,4-D amine in petri dishes, which is resulted in less radicle elongation especially in lower rates of herbicides in Sakarya population as compared to Düzce population that implies loss of effectiveness of herbicides in Sakarya population. Sakarya population from wheat field was found 1.36 times more resistant at $\mathrm{ED}_{50}$ and 2.53 times at $\mathrm{ED}_{90}$ to mesosulfuron+iodosulfuron+ mefenpir as compared to Düzce population from non-agricultural areas in a pot experiment. The result was interpreted as loss in efficiency of herbicide although it shows a partial resistance. It is concluded that the problem of catchweed bedstraw could increase due to its germination features and loss of herbicide efficiencies, which requires more and detailed researches.

Key words: 2,4-D amine, chlorsulfuron, herbicide resistance, mesosulfuron+iodosulfuron+methyl, propoxycarbazone+mezosulfuron+methyl, tribenuron+thifensulfuron.

\section{Giriş}

Galium (Rubiaceae familyasından) 667 tür ile Rubiae oymağının en çok türe sahip cinsidir (Yang ve ark., 2018). Bu cinsin Türkiye'de de 111 türü (tür altı birimlerle beraber 139) bulunmaktadır (Ehrendorfer ve Schonbeck-Temesy, 1982; Davis ve ark., 1988; Özhatay, 2000; Nezahat Gökyiğit Botanik Bahçesi, 2019). Bu türlerden dilkanatan (Galium aparine L.) birçok ülkede çok sayıda kültür bitkisinde mesele olarak rapor edilmiştir (Wilson ve Wright, 1990; Taylor, 1999; Bond ve ark., 2007; Milanova ve ark., 2007; Novak ve ark., 2009; Cirujeda ve ark., 2011; Saric ve ark., 2011; Leeson ve ark., 2012; Kolářová ve ark., 2014; Burton ve ark., 2017; Beckie ve ark., 2018; Deroo ve ark., 2018; CABI, 2019). Hatta beynelmilel ticaret ile ülkeden ülkeye de taşınabilmesinin yanında (Shimono ve Konuma, 2007) organik tarımda da önemli yabancıotlar arasında yer aldığı ifade edilmiştir (Lundkvist ve Verwijst, 2011). Dilkanatan, tohumluk italyan çimi (Lolium italicum L. cv. tetraflorum) yetiştiriciliğinde verimi \%30'dan daha fazla düşürmüştür (Vrbnicanin ve ark., 2012). Tahıl esaslı ekim sistemlerinde düşük yoğunluklarda bile önemli oranda verim ve kalite kayıplarına sebep olmakta ve hasadı geciktirmektedir (van der Weide, 1993; Ulber ve ark., 2010). Nitekim metrekarede 0,3-5 adet yoğunluklarda şeker pancarı, kışlık buğday ve mısırda önemli miktarda verim kaybı oluştuğu bildirilmiştir (van der Weide, 1993). Buğdayda dilkanatan yoğunluğuna göre (18-72 bitki/m²) verim kaybı \%4-32 arasında değişmiştir (Aziz ve ark., 2009). Başka bir çalışmada ise daha düşük yoğunluklarda (1-9 bitki/m²) da önemli kayıplar olduğu $(\% 3,17-14,60)$ ve dilkanatan için ekonomik zarar eşiğinin herbisite (terbutrin+triasülfüron, tifensülfüron+tribenuron veya klorsülfüron) ve yıla (1994-1997) bağlı olarak 0,4$2,1 \mathrm{bitki} / \mathrm{m}^{2}$ arasında değiştiği ve buğdayın bin dane ağırlığını da yani kaliteyi de etkilediği bildirilmiştir (Mennan, 1998). Son yıllarda Kanada'da kısmen herbisitlere dayanıklılık sebebiyle olsa da henüz tam olarak bilinmeyen sebeplerle Galium türlerinden dilkanatan ve yalancı yoğurtotunun (G. spurium) artış gösterdiği belirtilmektedir (Deroo ve ark., 2018). Türkiye'de de 2,4-D kullanımından dolayı diğer türlerin kontrol edilmesi sonucu dilkanatanın baskın tür hâline geldiği bildirilmiştir (Mennan, 1998).

Türkiye'de Galium türlerinden dilkanatan ve boynuzlu yoğurtotunun (G. tricornutum) bütün bölgelerde ve birçok kültür bitkisinde hem tarlada hem hasat edilmiş üründe bulunduğu tespit edilmiştir (Uludağ, 1993; Uludağ ve Katkat, 1993; Zel, 1994; Sırma ve ark., 1997; Mennan ve Işık, 2003; Yıldırım ve Ekim, 2003; Üremiş, 2005; Üremiş ve ark., 2013; Gökalp ve Üremiş, 2015; Şin ve ark., 2016; Soylu ve ark. 2017; Arslan, 2018; Bozkurt ve Tursun, 2018). Bunun sebebi belki de bazı yerlerde dilkanatanın hem yaz hem kış populasyonlarının bulunmasıdır (Mennan ve Ngouajio, 2006), bu popülasyonların çimlenme oranları da yıldan yıla değişiklik göstermektedir (van den Brand, 1984). Dilkanatanın en iyi \%75 tarla kapasitesindeki nemde çimlendiği (Solak, 2007), dilkanatan, yalancı yoğurtotu ve boynuzlu yoğurtotunun en iyi çimlenme oranının kış popülasyonunda görüldüğü ve ilkbahar popülasyonunun yağış olmazsa çimlenmediği rapor edilmiştir (Royo-Esnal ve ark., 2010). Bu iki tür dışında yabancıot olarak Türkiye'de kaydedilen başka Galium türleri de vardır: $G$. incanum, $G$. rotundifolium, $G$. samuelssonii, G. aucheri, G. floribundum subsp. floribundum, G. spurium L. subsp. spurium, $G$. verticillatum, G. verum subsp. glabrescens, G. verum subsp. verum (Uluğ ve ark., 1993; Yıldırım ve Ekim, 2003).

Çok düşük yoğunluklarda bile verimi etkileyen ve son yıllarda daha fazla mesele olduğu ifade edilen dilkanatandan Sakarya ilinde de buğday üreticileri şikâyet etmektedir. Meselenin ne olduğunu anlayabilmek için dilkanatan mücadelesinin bu 
aşamada ne durumda olduğunun bilmek ve biyolojisi üzerinde bilgi sahibi olmak icap etmektedir. Çimlenme ve erken gelişim biyolojisi bu bağlamda önem arz etmektedir. Çalışmalarda yöntemler arasındaki ve tohum kaynaklarındaki farklılıklar sonuçları da etkileyebilmektedir. Nitekim popülasyonlar arasındaki ve farklı ana bitkilerin ürettiği tohumlardaki farklılıklar çimlenme zamanı, sıcaklığı vb konuları etkilemiştir (Christal, 2000).

Dilkanatan mücadelesinde ALS enzimini etkileyen herbisitlerden sülfonilüreli herbisitler bilhassa buğday tarlalarında yoğun olarak kullanılmaktadır. Türkiye'de ruhsatlı olan ve etiketlerinde dilkanatan bulunan etkili maddeler şunlardır: 2,4-D etil heksilester, 2,4-D dimetil amonyum tuzu, aklonifen, amidosülfüron, aminopiralid, bentazon, bromoksinil oktanoat, desmedifam, dikamba, diklorprop, diflufenikan, etametsülfüron-metil, etofumesat, florasulam, flufenaset, fluroksipir, glifosat, glifosat asit, glifosat potasyum tuzu, glifosat amonyum tuzu, haloksifenmetil, imazamoks, iyodosülfüron-metil sodyum, karfentrazon etil, kloridazon, klorsülfüron, klomazon, klopiralid (dikloropikolinik asit), MCPA, mekoprop, metribuzin, metsulfüron-metil, mezosülfüron-metil, oksiflorfen, pendimetalin, fenmedifam, pikloram, piroksasülfon, pirokssulam, sülfosülfüron, tienkarbazon-metil, tifensülfüron-metil, triasülfüron, tribenuron-metil yer almaktadır (BKÜDB, 2019). Ancak bu etkili maddelerin bazıları, dilkanatana yeterli etkiyi tek başına gösteremese de karışımların içerisinde daha fazla sayıda türü daha etkili kontrol edebilmek amacıyla bulunmaktadır. Bazı etkili maddelerle beraber deklokuintoset-asit, klokuintoset-meksil ve mefenpir-dietil gibi koruyucular (safener) da kullanılmıştır.

Ancak herbisitlerin kullanılmaya başlanması ile beraber, bazı herbisitlerin başta etkili oldukları bazı yabancıotlara karşı etkilerinde azalma olduğuna dair ilk yayınlar 1950'lerde başlamasına rağmen, ilk herbisitlere dayanıklı yabancıot vakası 1960'ların sonunda ortaya konulmuştur (Ryan, 1970; LeBaron, 1982) Herbisitlere dayanıklılık vakaları Türkiye'de de ilk tespit edilen yabanî yulafın herbisitlere dayanıklılık kazanmasından bu yana artış göstermektedir (Uludağ ve ark., 2007; Heap, 2019; İnci ve ark., 2019). Buğday tarlalarında önemli bir mesele haline gelen türler arasında dilkanatan, boynuzlu yoğurtotu ve yalancı yoğurtotu yer almaktadır ve bu üç türün değişik herbisitlere oluşturduğu dayanıklılık vakası sayısı ondur (Beckie ve ark., 2013; Heap, 2019). Güney Avustralya'da boynuzlu yoğurtotu imazamoks, imazapir, iyodosülfüron ve pirokssulam etkili maddelerine çapraz dayanıklılık oluşturmuştur. Kanada'da yalancı yoğurtotu imazethapir, metsülfüron, kuinklorak, sülfometuron, tifensülfüron, triasülfüron ve tribenurona çoklu dayanıklılık geliştirmiştir. Dilkanatanın da herbisitlere hem çoklu dayanıklı hem de çapraz dayanıklı popülasyonları bildirilmiştir. Türkiye'de de dilkanatanın herbisitlere karşı oluşturduğu dayanıklılık konusunda çalışmalar yapılmıştır. İç Anadolu ve Karadeniz Bölgelerinden toplanan 1359 popülasyonla yapılan çalışmada pyroksisulam+klokuintoset ve dikamba+triasülfüron'da etki kaybı, tribenurona dayanıklı popülasyonlar $(0,5-8,8$ kat arasında dayanıklı 17 popülasyon) başta olmak üzere 23 dayanıklı popülasyon tespit edildiği bunların bazılarında çapraz bazılarında da çoklu dayanıklılık olduğu fakat etki yerinde bir mutasyon olmadı̆̆ bildirilmiştir (Kaya Altop ve ark., 2017).

Dünya çapında yaklaşık 220 milyon hektar alanda buğday yetiştiriciliği yapılmaktadır (Uludağ, 2017). Türkler için buğday temel gıda maddesi olarak asırlardır önem arzetmektedir. Sakarya ili buğday yetiştiriciliğinin yapıldığı önemli merkezlerden biri olup, buğdayda kullanılan herbisitlerin etkinliğinin azaldığına dair şikayetler giderek artmaktadır. Bu sorulara cevap bulabilmek amacıyla dilkanatanın çimlenme biyolojisi ve bazı herbisitlere tepkisi üzerinde çalışılmıştır.

\section{Materyal ve Yöntem}

Dayanıklılık şüphesi olan biyotipe ait tohumlar Sakarya Tarım Araştırma Enstitüsü tarlalarından 2016 yılında hasat edilen buğday ürününün selektörden geçirilmesi sırasında selektör artıklarından elde edilmiştir (Sakarya popülasyonu). Şahit popülasyonun tohumları Düzce ilinden herbisit uygulanmamış tarım dışı alandan 2017 yılı Haziran ayında toplanmıştır (Düzce popülasyonu). Denemelerde Çizelge 1'de özellikleri verilen herbisitler kullanılmıştır.

\section{Dilkanatanın çimlenme sıcaklıklarının belirlenmesi}

Sakarya popülasyonunun tohumları ile yürütülen çimlendirme denemeleri, her petri bir tekerrür olacak şekilde dört tekerrürlü olarak $4^{\circ} \mathrm{C}$ ve $10^{\circ} \mathrm{C}$ için 17 Ocak 2017 tarihinde, $15^{\circ} \mathrm{C}$ ve $20^{\circ} \mathrm{C}$ için 15 Mayıs 2017 tarihinde; ikinci tekrarları ise, sırasıyla 21 Ocak 2017 ve 19 Mayıs 2017 tarihinde başlatılmıştır. Tabanına iki kat filtre kağıdı yerleştirilmiş $9 \mathrm{~cm}$ çaplı petrilere 25 adet tohum konulmuş ve $5 \mathrm{ml}$ su verilerek inkubatörlere $\left(4^{\circ} \mathrm{C}\right.$ için laboratuvar buzdolabı) yerleştirilmiştir. İstenilen sıcaklıklara ayarlanmış inkübatörlerde denemeler, tesadüf blokları deneme deseninde bloklama faktörü tekerrürün kuruluş günü 
olacak şekilde zaman içinde bloklandırılarak kurulmuştur. Petri içerisinde yer alan tohumların nemli kalmasını sağlanmak amacıyla sayım yapılırken gerekenlere saf su ilave edilmiştir. Çimlenen tohumlar dördüncü günden itibaren her gün sayılarak ortamdan uzaklaştırılmış ve her bloktaki sayımlar 21 nci günde sona erdirilmiştir.

Çizelge 1. Tarla ve laboratuvar denemelerinde kullanılan herbisitler

\begin{tabular}{cccc}
\hline Etkili madde & Tavsiye dozu (prep.) & Ticari adı & Firması \\
\hline $\begin{array}{c}\text { lyodosülfüron-metil-sodyum+mezosülfüron- } \\
\text { metil+mefenpir-dietil }\end{array}$ & $250 \mathrm{~g} \mathrm{ha}^{-1}$ & Atlantis WG & Bayer \\
$\begin{array}{c}\text { Propoksikarbazon-sodyum+ mezosülfüron- } \\
\text { metil+mefenpir-dietil } \\
\text { Klorsülfüron }\end{array}$ & $250 \mathrm{~g} \mathrm{ha}^{-1}$ & Attribute Super WG & Bayer \\
2,4-D dimethyl amin tuzu & $7,5 \mathrm{~g} \mathrm{ha}^{-1}$ & Glean $75 \mathrm{DF}$ & Dupont \\
Tribenuron-metil+tifensülfüron-metil & $2000 \mathrm{ml} \mathrm{ha}^{-1}$ & Di-Amin $500 \mathrm{SL}$ & Safa Tarım \\
\hline
\end{tabular}

\section{Farklı herbisitlerin iki farklı dilkanatan populasyonuna etkisi}

Bu amaçla biri petrilerde beş farklı herbisit ile diğeri saksıda bir herbisit ile iki populasyonu karşılaştırmak amacıyla iki farklı deneme kurulmuştur. Petri denemeleri herbisitlere karşı oluşan dayanıklılığın hızla belirlenmesinde kullanılan yöntemlerdendir (Uludag ve ark., 2005; Uludag ve ark., 2006; Tursun, 2012). Dozatepki denemeleri ise ayrıntılı sonuçlar elde edebilmek için yürütülen denemelerdir (Seefeldt ve ark.,1995).

Illk deneme olan petri denemesi, her petri bir tekerrür olacak şekilde dört tekerrürlü ve iki tekrarlı olarak 23 Ekim 2017 ve 24 Mart 2018 tarihlerinde sıcaklığı $10^{\circ} \mathrm{C}$ olarak ayarlanmış bir inkübatörde kurulmuştur. Petrilere iki kat filtre kâğıdı üzerine 25'er tohum yerleştirilmiştir. Çalışmada daha önceki dayanıklılık ve mücadele çalışmalarında kullanılmış herbisitlerin incelenmesi sonucu seçilen beş herbisit formülasyonu kullanılmıştır (Çizelge 1). Herbisitler uygulama dozunun $1 / 2,1,2$ ve 4 katı dozlarında olacak şekilde petri içerisine $5 \mathrm{ml}$ mahlül olarak uygulanmıştır. Şahitte sadece saf su kullanılmıştır. Çalışmanın 30uncu gününde her petrideki çimlenen tohum sayısı kaydedilmiş ve bunların kök uzunlukları ölçülmüştür. Toplam kök uzunluğu petrideki toplam tohum sayısına bölünerek herbisitlerin kök uzunluğuna etkisi hesaplanmıştır. Veriler varyans analizine tabi tutulmuştur.

Her iki popülasyonla sadece iyodosülfüron+mezosülfüron+mefenpir kullanılarak ikinci bir deneme yürütülmüştür. Tohumdan üretilen fideler her saksıya bir bitki olacak şekilde $9 \mathrm{~cm}$ çaplı saksılara şaşırtılarak gündüz $15^{\circ} \mathrm{C}, \% 65$ nem; gece $12^{\circ} \mathrm{C}, \% 60$ neme ayarlanmış iklim dolabına alınmıştır. Saksıların doldurulması için kullanılan harç 1:1:1 oranında; torf, toprak ve perlit karışımı yapılarak elde edilmiştir. Deneme tesadüf blokları deneme desenine göre (bitki gelişmesine göre bloklanmış) kurulup, dört tekerrürlü olarak gerçekleştirilmiştir. Saksılar ilaçlamadan sonra $20 \pm 2^{\circ} \mathrm{C}^{\prime}$ sıcaklığa ve \%75 nisbî neme ayarlanmış iklim dolabına konmuştur. Herbisit uygulama dozunun $0,1 / 2,1,2$ ve 4 katı dozlarda 3 Atm sabit basınçla yelpaze hüzmeli meme (teejet XR10002) kullanılarak Honda WRJ2225 pülverizatör ile bitkiler 26 yapraklı dönemdeyken uygulanmıştır. Uygulamadan sonraki 14üncü gün sonunda toprak seviyesinden kesilerek hasat edilen bitkiler kağıt torbalara konularak etüvde $65^{\circ} \mathrm{C}^{\prime}$ de 48 saat kurutularak ve kuru biyokütle ağırlıkları dozatepki çalışmalarına esas olacak verileri oluşturmuştur. Verilere $\mathrm{R}$ istatistik programında regresyon analizi uygulanmıştır. Veriler üç sabitli log-logistik denklemine uymuştur:

$$
Y=(d /(1+E X P(b *(\operatorname{LOG}(D)-L O G(e)))))
$$

Burada: D uygulanan herbisit miktarını, d, b ve e sabit değerleri ifade etmektedir (Seefeldt ve ark., 1995). Daha sonra bitkilerde \%50 azalmaya sebep olan doz hesaplanarak dayanıklılık indeksi elde edilmiştir.

\section{Bulgular ve Tartışma}

\section{Dilkanatanın çimlenme sıcaklığının belirlenmesi}

Dilkanatanın çimlenme özelliklerini belirlemek amacıyla dört farklı sıcaklıkta yapılan denemede $20^{\circ} \mathrm{C}$ 'de herhangi bir çimlenme olmamıştır. En yüksek çimlenme $\% 93,5$ ile $10^{\circ} \mathrm{C}^{\prime}$ de elde edilmiştir, bunu $\% 71,5$ ile $4^{\circ} \mathrm{C}$ ve 34,5 ile $15^{\circ} \mathrm{C}$ tâkip etmiştir (Şekil 1 ). Nitekim, dilkanatanın $1-25^{\circ} \mathrm{C}$ arasında, sabit sıcaklıklar da dâhil, çimlenebilmesine rağmen, genç tohumlarının $2-10^{\circ} \mathrm{C}$, yaşlı tohumlarının $10-20^{\circ} \mathrm{C}$ aralığında daha fazla çimlendiği belirtilmiştir (van den Brand, 1984). Bu çalışmada düşük sıcaklık denemeleri $\left(4-10^{\circ} \mathrm{C}\right)$ altı aylık, yüksek sıcaklık denemeleri (15$\left.20^{\circ} \mathrm{C}\right) 11$ aylık tohumlarla yapılmış olmasına rağmen, daha yüksek çimlenme oranları düşük sıcaklıklarda 
belirlenmiştir. Yani bir yaşa kadar tohumların genç tohum addedilmesi gerektiği (üst sınırı bu bulgularla söylenemez) tarafımızdan ortaya konulmuştur. Tam aksine başka çalışmada ise çimlenme dizgesi daha geniş bir aralıkat, $5-30^{\circ} \mathrm{C}$ arası olarak bildirilmiş ve en uygun (optimum) çimlenme sıcaklığı $10^{\circ} \mathrm{C}$ olarak belirlenmiştir (Christal, 2000). Konya'da yapılan bir çalışmada ise en düşük çimlenme aralığı $0-2^{\circ} \mathrm{C}$ ve en yüksek çimlenme aralığı $25-30^{\circ} \mathrm{C}\left(30^{\circ} \mathrm{C}\right.$ 'de çimlenme olmamıştır) ve en uygun çimlenme aralığı da $5-25^{\circ} \mathrm{C}$ olarak bildirilmiştir (Solak, 2007). Samsun'da yapılan bir çalışmada dilkanatanın dört aylık tohumları hiç çimlenmezken, altı aylık tohumları $5^{\circ} \mathrm{C}$ 'nin altında ve $25^{\circ} \mathrm{C}$ 'nin üzerinde çimlenememiş, 12 aylık tohumlar $2^{\circ} \mathrm{C}^{\prime} \mathrm{de}$, altı aylık tohumlar en yüksek oranda $15^{\circ} \mathrm{C}^{\prime}$ de (\%29) ve 12 aylık tohumlar $10^{\circ} \mathrm{C}^{\prime}$ de $(\% 68,5)$ çimlenmiştir (Mennan, 1998). Boynuzlu yoğurtotu en iyi çimlenmiş ancak çeşitli uygulamalara rağmen çimlenme oranı \%50'yi geçmemiştir ve $20^{\circ} \mathrm{C}$ 'de çok düşük çimlenme olmuştur (Uludag ve Özer, 1999). Boynuzlu yoğurtotu ile yapılan başka bir çalışmada bir, altı ve 12 aylık tohumlarda neredeyse hiç çimlenme olmamıştır; ancak sülfürik asit ve giberalik asit kullanılarak dormansi kırıldıktan sonra $10^{\circ} \mathrm{C}^{\prime} \mathrm{de}$ çimlenme oranı \% 60'। geçmesine rağmen, $20^{\circ} \mathrm{C}$ 'de hemen hemen hiç çimlenme olmamıştır (Taştan ve ark., 1993).

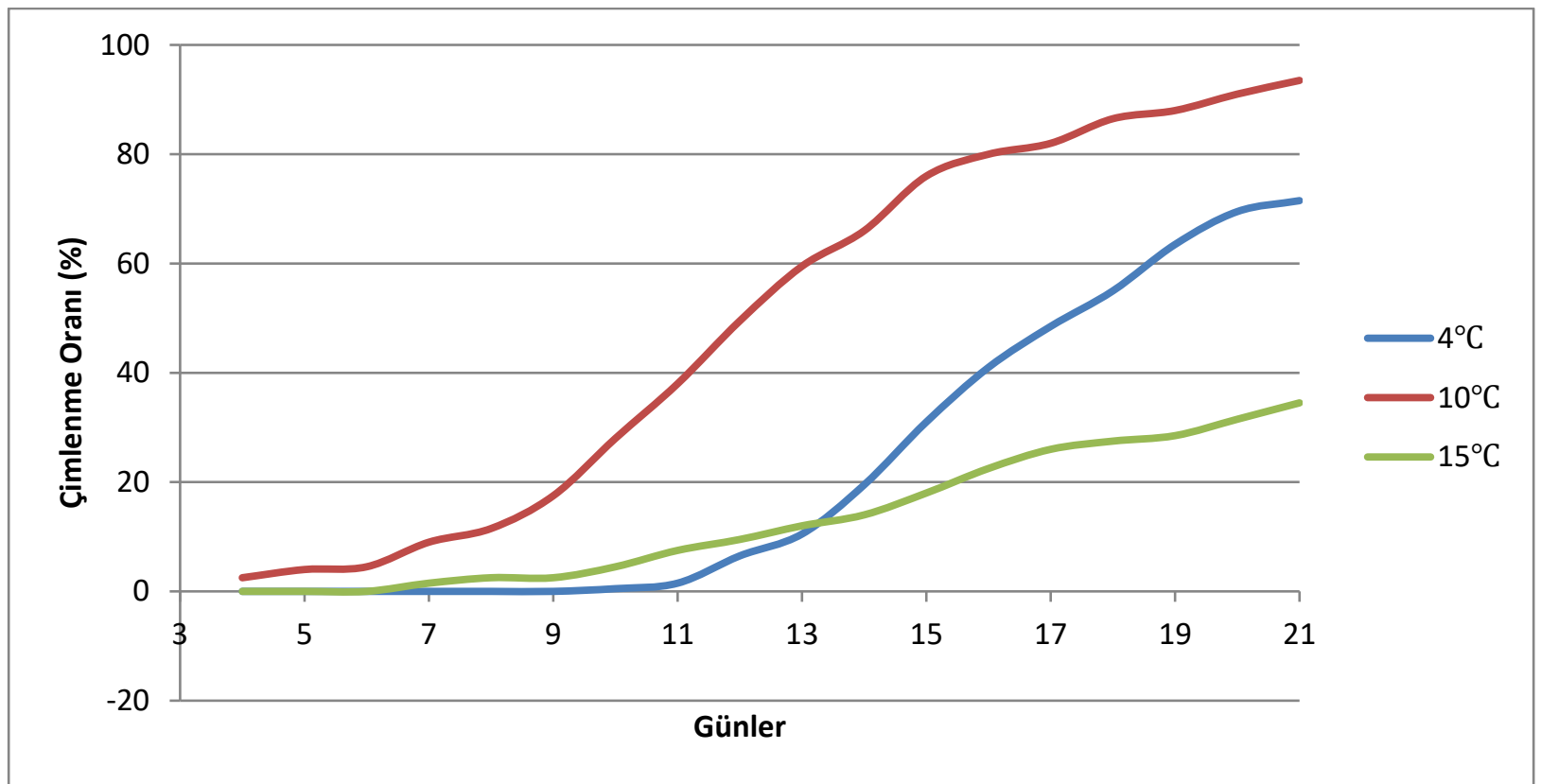

Şekil 1. Farklı sıcaklıkların dilkanatanın çimlenmesine etkisi.

Çimlenme $10^{\circ} \mathrm{C}^{\prime}$ de, dördüncü günde, $15^{\circ} \mathrm{C}^{\prime}$ de yedinci ve $4^{\circ} \mathrm{C}^{\prime}$ de ise 11 nci günde başlamıştır. En yüksek çimlenme oranının gerçekleştiği $10^{\circ} \mathrm{C}^{\prime}$ de çimlenme hızı da en yüksek bulunmuştur. Çimlenme oranının aksine, çimlenme hızı $15^{\circ} \mathrm{C}^{\prime}$ de $4^{\circ} \mathrm{C}^{\prime}$ ye göre daha yüksek olmuştur. Başka bir çalışmada çimlenme 15 ve $20^{\circ} \mathrm{C}^{\prime}$ de yedinci günde, 2 ve $5^{\circ} \mathrm{C}^{\prime}$ de 21 nci günde başlamıştır (Mennan, 1998). Tohumların tamamen çimlenmemesinin de durgunluktan (dormansi) kaynaklandığı belirtilmiştir (Taştan ve ark., 1993; van der Weide, 1993; Mennan, 1998; Christal, 2000; Bond ve ark., 2007). Birincil durgunluğu üç ayda kırılan dilkanatan, kışın düşük sıcaklıklardan dolayı mecburî durgunluğa ve yüksek sıcaklıklarda teşvik edilmiş durgunluğa girmekte ve mecburî durgunluğu yine yüksek sıcaklıklar tarafından kırılmaktadır (van der
Weide, 1993). Arazide yapılan çalışmalarda ise birincil durgunluğun sonbaharda sona erdiğini, teşvik edilmiş durgunluğun ise erken yazda başladığını, ancak teşvik edilmiş durgunluğa rağmen dar bir sıcaklık aralığında çok az çimlenmenin gerçekleşebildiği ortaya konulmuştur (Christal, 2000). Dilkanatan topraktaki tohum rezervindeki geçici türlerdendir, populasyonu yıllık olarak \%80 civarında azalmaktadır (Barralis ve ark., 1988; Christoffoleti ve Caetano, 1998).

Dilkanatanın, hatta aynı cinsten olan boynuzlu yoğurtotunun farklı populasyonlarının çimlenme ve çıkış özelliklerinde durgunluk (dormansi) gibi birçok unsurun rol oynadığı ve çok kesin sonuçlara da ulaşmanın mümkün olmadığı daha önceki çalışmalarda ifade edilmiştir (van den Brand, 1984; Uludağ ve Özer, 1999). Ancak, üzerinde çalışılan 
populasyon itibari ile dilkanatanın en uygun çimlenme sıcaklığının çimlenme oranı ve çimlenme hızı açısından $10^{\circ} \mathrm{C}$ civarında olduğu ve daha düşük sıcaklıklarda çimlenme hızı düşük olsa da çimlenmenin kış sonrası

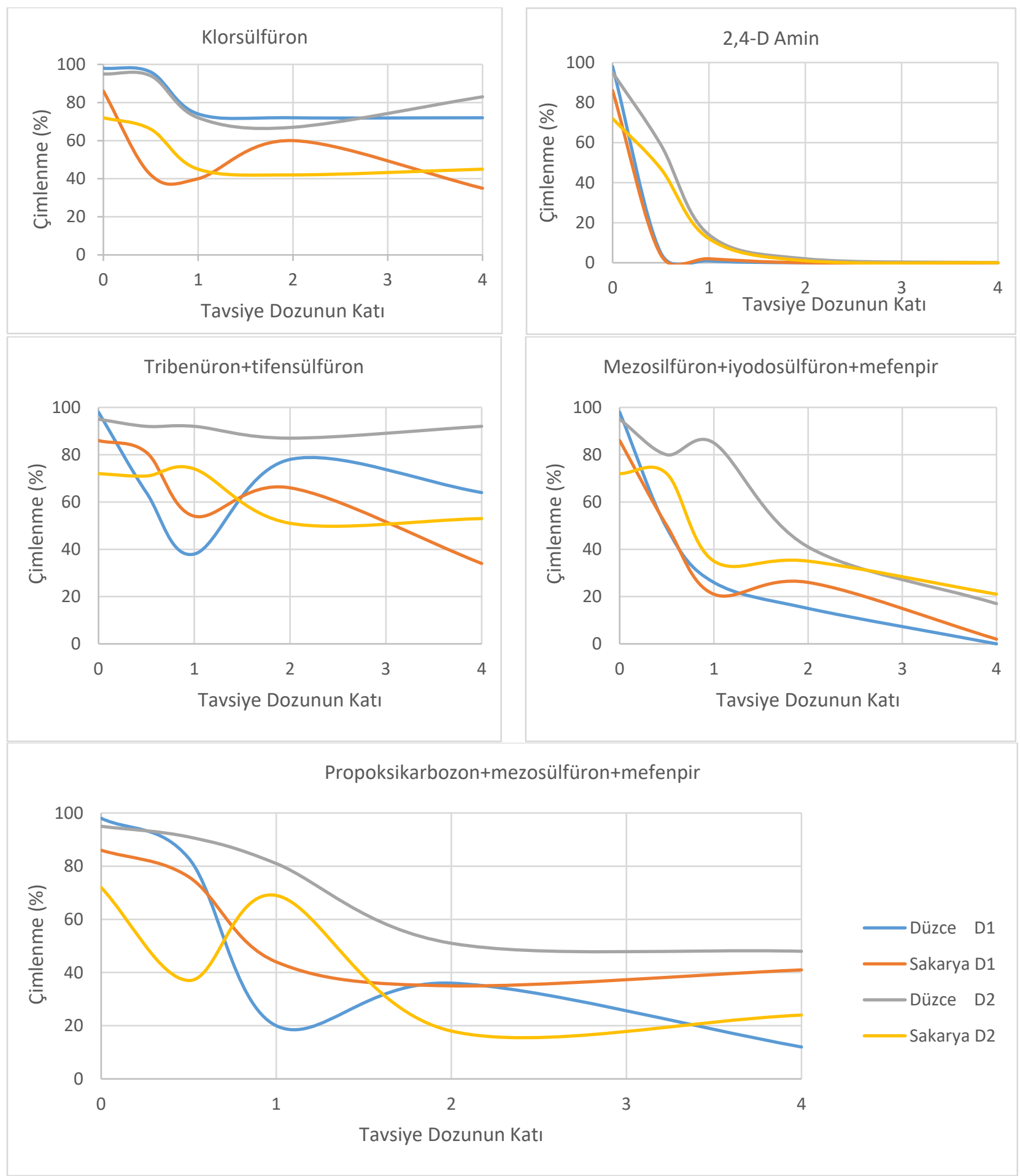

Şekil 2. Herbisitlerin dilkanatanın iki farklı popülasyonunun çimlenmesine etkisi (D: deneme). hemen başlayacağı ve rekabetin de buna bağlı olarak daha erken başlayabileceği kanısına varılmıştır. 


\section{Farklı herbisitlerin iki farklı dilkanatan populasyonuna etkisi}

Herbisit uygulamalarının Düzce popülasyonu ve muhtemel dayanıklı Sakarya Popülasyonuna etkilerini belirlemek amacıyla yapılan petri denemesinde ilâçsız şahitte ilk denemede, sırasıyla
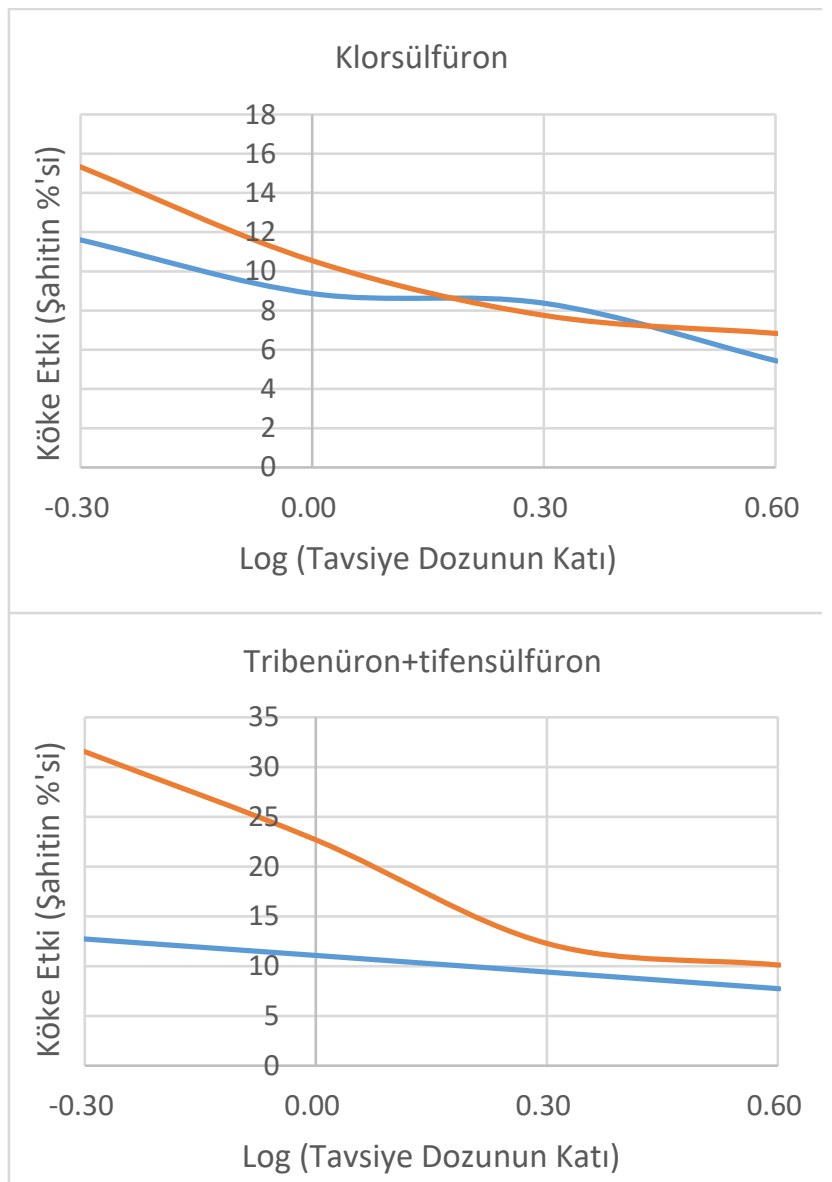

$\% 98$ ve $\% 86$, ikinci denemede $\% 95$ ve $\% 72$ oranında çimlenme elde edilmiştir. Uygulamalarda elde edilen çimlenme değerleri her iki deneme için ayrı ayrı verilmiştir (Şekil 2).
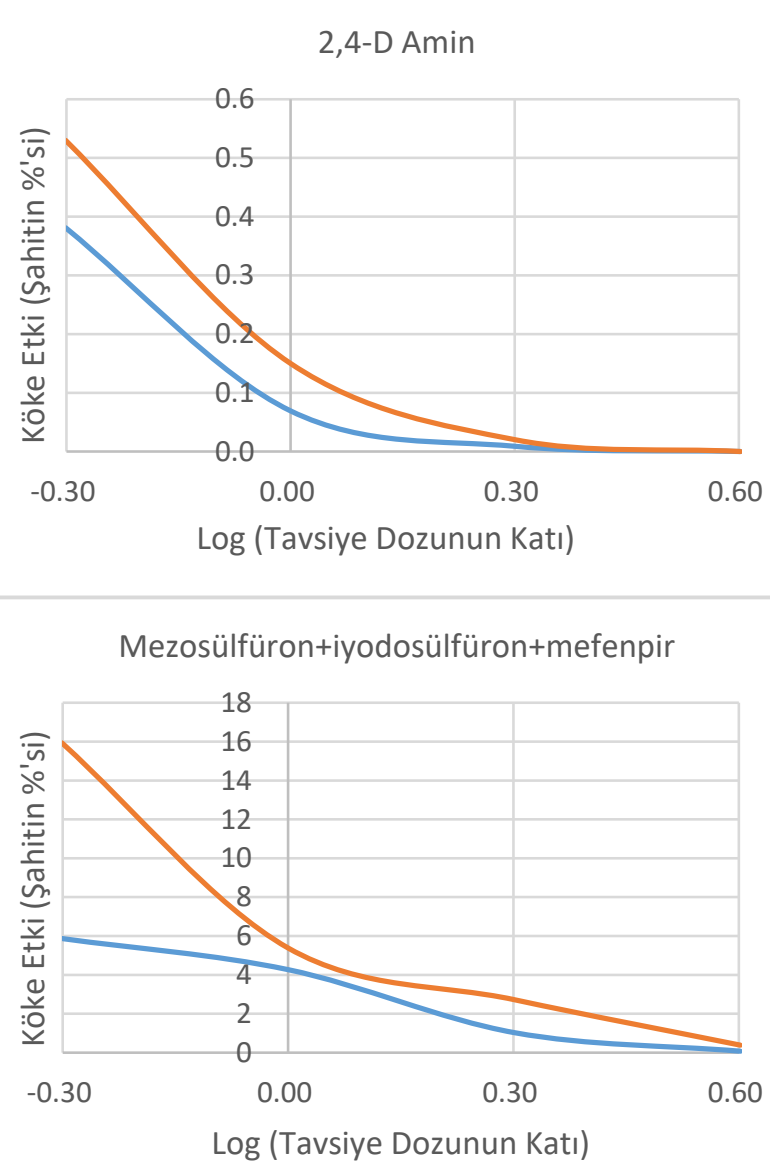

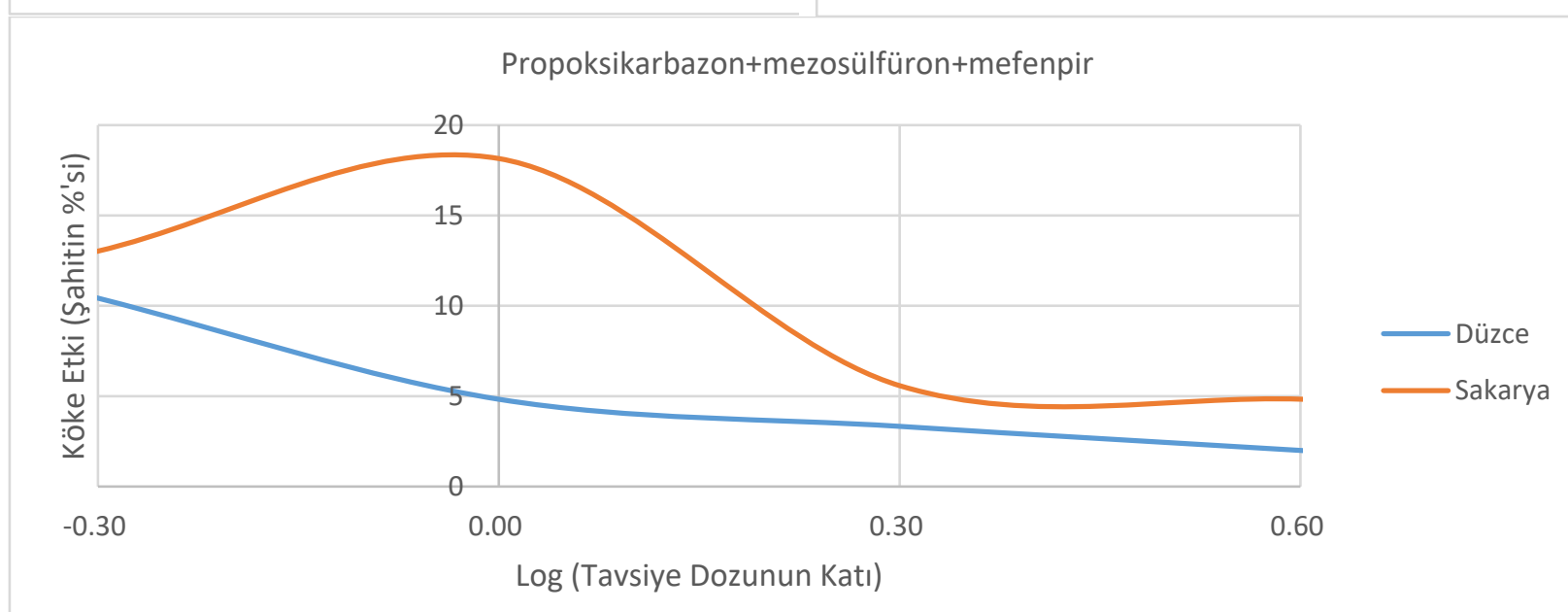

Şekil 3. Herbisitlerin dilkanatanın iki farklı popülasyonunun kökçük uzunluğuna etkisi 
Bütün herbisitlerin yüksek dozlarında her iki populasyonun da çimlenme oranı düşmüştür. Bilhassa 2,4-D aminin iki ve dört kat dozlarında ve mezosülfüron+iyodosülfüron karışımının dört kat dozunda hemen hemen hiç çimlenme olmamıştır. Aksine diğer üç herbisitte artan dozlarla birlikte düşme olmasına rağmen çimlenme oranı bu nispette düşmemiştir. $\mathrm{Bu}$ deneme bu herbisitlerin etki mekanizmasına yönelik olmadığı için bu yönleriyle tartışılmamıştır. Ancak bütün herbisitler genel olarak Sakarya popülasyonunun çimlenmesini daha fazla azaltmıştır. Bu durum herbisitlere dayanıklılıkla ilgili olmayıp popülasyonların toplandıkları yerler ve şartlarla ilişkili olabilir. Nitekim, daha önce de belirtildiği gibi çimlenme üzerinde ana bitkiden, yetişme alanından ve coğrafyasından kaynaklanan farklılıkların olması normal bir durumdur

Herbisitlerin hepsi uygulamasız şahite göre kök uzunluklarını çok belirgin bir şekilde azaltmıştır (Şekil 3). Ancak 2,4-D’nin en düşük dozunda daha az bir etki görülmüştür. Bütün herbisitler her iki populasyonun kök uzunluğunu doz arttıkça daha fazla etkilemiştir. Sakarya popülasyonunun kök uzunlukları Düzce popülasyonuna göre daha az etkilenmiştir. Hem ALS hem de oksin grubu herbisitlerde bitkilerin köklerinde de zarar belirtileri görülmektedir. Burada muhtemel dayanıklı Sakarya popülasyonunun daha az etkilenmesi herbisitlerin daha az etkili olmasından kaynaklanmış olabilir. ALS grubu herbisitlerden tribenuron+tifensülfürona ve klorsülfürona dayanıklı dilkanatan popülasyonları Türkiye'de daha önce tespit edilmiştir (Kaya Altop ve ark., 2017; Heap, 2019). İran'da 2,4-D dahil oksin grubu herbisitlere, Çin'de de diğer oksin grubu herbisitlere dayanıklı dilkanatan kayıtları mevcuttur (Heap, 2019). Türkiye'de 2,4-D başka etkili maddelerle karışım olarak ruhsatlıdır, ancak 2,4-D dilkanatanı tek başına yeterince kontrol edememektedir (Mennan, 1998; Yavuz, 2013; BKÜDB, 2019). İran'la ilgili dayanıklılık vakasını da bu bilgiler bağlamında değerlendirmek gerekmektedir. Bu çalışmada ele alınan diğer bütün etkili maddeler ALS grubu herbisitlerdir ve bunlarla ilgili dilkanatana karşı etki azalması ve dayanıklılık vakaları bilinmektedir.

Mezosülfüron+iyodosülfüron karışımının farklı dozlarının dilkanatanın iki farklı popülasyonunun kuru ağırlıklarına etkisi Çizelge 2'de verilmiştir. Veriler üç sabitli log-logistic modele uymuştur ve hesaplanan sabit değerler her iki popülasyon için de istatistik açıdan manidar bulunmuştur.

Çizelge 2. Dilkanatanın iki farklı popülasyonun regresyon analizi sonuçları

\begin{tabular}{ccccccc}
\hline \multirow{2}{*}{ Sabitler } & \multicolumn{3}{c}{ Düzce popülasyonu } & \multicolumn{3}{c}{ Sakarya popülasyonu } \\
\cline { 2 - 7 } & $\begin{array}{c}\text { Hesaplanan } \\
\text { değer }\end{array}$ & $\begin{array}{c}\text { Standart } \\
\text { hata }\end{array}$ & P değeri & $\begin{array}{c}\text { Hesaplanan } \\
\text { değer }\end{array}$ & $\begin{array}{c}\text { Standart } \\
\text { hata }\end{array}$ & P değeri \\
\hline b & 1.4290963 & 0.2874887 & $1.16 \mathrm{e}-04 * * *$ & 1.018379 & 0.356420 & $0.010906^{*}$ \\
d & 0.1233151 & 0.0078866 & $1.60 \mathrm{e}-11 * * *$ & 0.115709 & 0.012224 & $3.44 \mathrm{e}-08^{* * *}$ \\
$\mathrm{e}$ & 1.0284965 & 0.1620548 & $7.30 \mathrm{e}-06^{* * *}$ & 1.398476 & 0.470835 & $0.008583^{* *}$ \\
\hline
\end{tabular}

Elde edilen verilere göre log logistic eğrileri Şekil 4'te verilmiştir. Hesaplanan $\mathrm{ED}_{50}$ değeri Düzce popülasyonu için $1.02850 \pm 0.16205$ ve Sakarya popülasyonu için 1.39848+0.47084 bulunmuştur. ED 90 değerleri ise $4.78550 \pm 1.42262$ (Düzce) ve $12.09695+8.89988$ (Sakarya) olarak hesaplanmıştır. Dayanıklılık indeksi ED 50 'ye göre 1,36 kat, ED90'a göre 2.53 olarak belirlenmiştir. Bu bulgu bize tam bir dayanıklılık oluştuğunu göstermese de bir etki kaybının oluştuğu aşikârdır. Türkiye'de yapılan bir çalışmada mezosülfüron+iyodosülfüron+mefenpir, tribenuron+tifensülfüron, dicamba+triasülfüron ve klorsülfüron dilkanatanı yeteri kadar kontrol edememiştir (Mennan ve ark., 2011). Diğer bir bir çalışmada ise 23 dilkanatan popopulasyonunda herbisitlere dayanıklılık 278'inde ise dayanıklılık şüphesi tespit edilmiştir (Kaya Altop ve ark., 2017). Dayanıklı populasyonlardan 16 tanesi mezosülfüron+iyodosülfüron karışımına dayanıklılık göstermiştir ve diğer bazı ALS herbisitlere de çapraz dayanıklık göstermiştir.

Bu çalışma ile dilkanatanın en uygun çimlenme sıcaklığının $10^{\circ} \mathrm{C}$ civarında olmasından ve daha düşük sıcaklıklarda çimlenme hızı düşük olsa da kış sonrası hemen çimleneceğinden dolayı rekabetin de buna bağlı olarak daha erken başlayabileceği kanısına varılmıştır. Ayrıca, denenen herbisitlerde tarla populasyonunun boş alan populasyonuna göre herbisitlerden daha az etkilenmesi ve mezosülfüron+iyodo- sülfüron+mefenpir herbisitinde tarla populasyonunda boş alan populasyonuna nispeten etki düşüklüğü görülmesi dilkanatanın daha önemli hâle gelebileceğini ve üzerinde daha ayrıntılı ve fazla araştırma ihtiyacı olduğunu göstermiştir. 


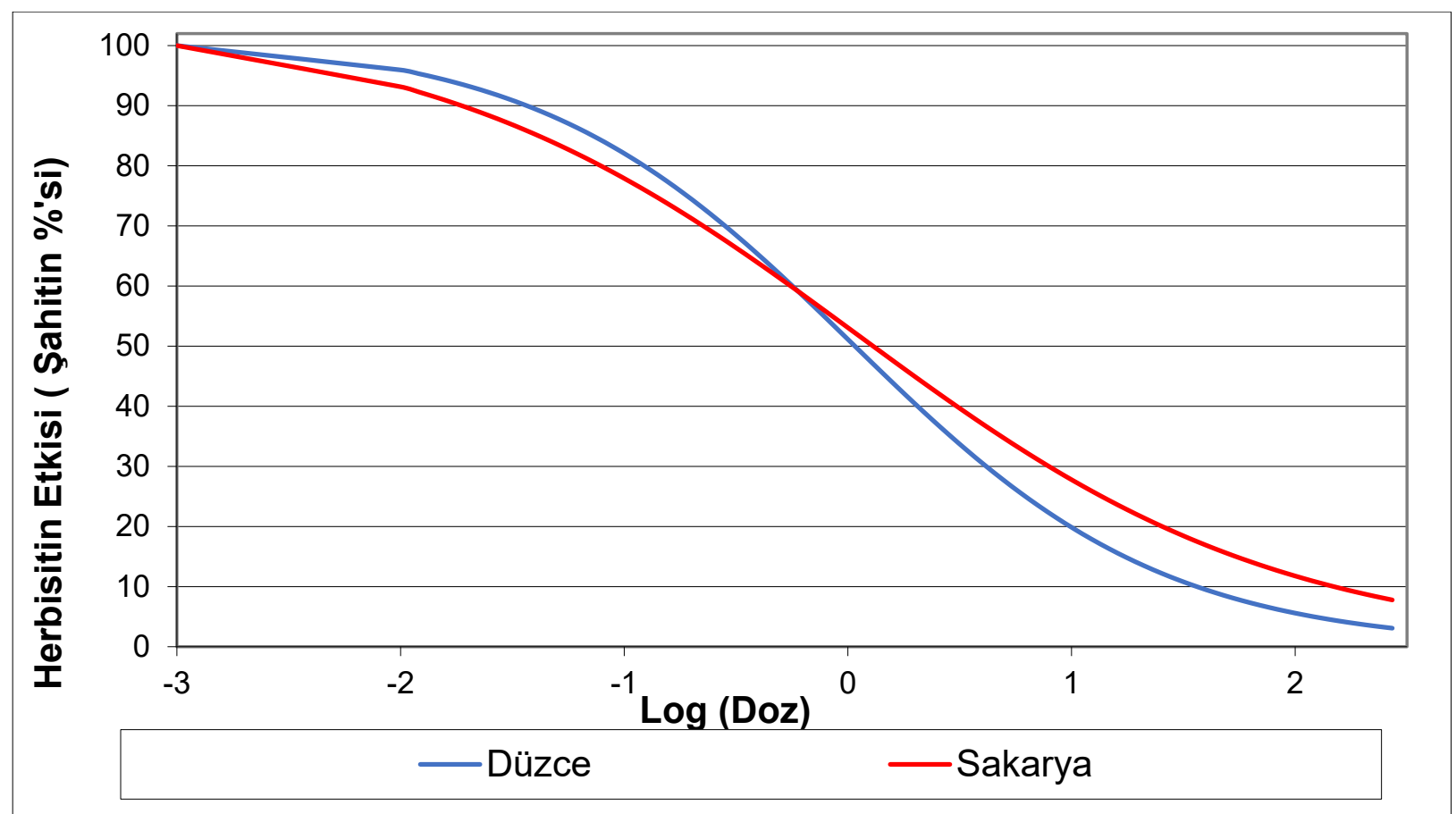

Şekil 4. Dilkanatanın iki farklı populasyonunun Mezosülfüron+iyodosülfüron+mefenpir uygulanmasına dozatepki eğrisi.

\section{Teşekkür}

Denemelerin yürütülmesi esnasındaki yardımlarından dolayı Dr. Z. Filiz Arslan, Dr. Khawar Jabran ve Ziraat Yüksek Mühendisi Şadiye Zambak'a, makalenin yazılmasındaki kritik desteklerinden dolayı Dr. A. Tansel Serim ve Ziraat Yüksek Mühendisi Deniz Inci'ye teşekkür ederiz.

¥:Bu makale Düzce Üniversitesi Fen Bilimleri Enstiüsünde yürütülen yüksek lisans tez çalışmasından üretilmiştir.

\section{Kaynaklar}

Arslan, Z.F. 2018. Decrease in biodiversity in wheat fields due to changing agricultural practices in five decades. Biodiversity and Conservation, 27: 3267-3286.

Aziz, A., Tanveer, A., Ali, A., Yaseen, M. 2009. Density dependent interactions between cleavers (Galium aparine) and wheat (Triticum aestivum) planted at different times. Pakistan Journal of Agricultural Sciences, 46(4): 258-265.

Barralis, G., Chadoeuf, R.E.T., Lonchamp, J.P. 1988. Longevité des semences de mauvaises herbes annuelles dans un sol cultivé. Weed Research, 28: 407-418.
Beckie, H.J., Lozinski, C., Shirriff, S., Clark, A.B. 2013. Herbicide-Resistant Weeds in the Canadian Prairies: 2007 to 2011. Weed Technology, 27(1): 171-183.

Beckie, H.J., Shirriff, S.W., Leeson, J.Y. 2018. Manitoba Weed Survey of Herbicide Resistant Weeds in 2016. Agriculture and Agri-Food Canada, Saskatoon Research \& Development Centre, Saskatoon, Saskatchewan, Canada $39 \mathrm{~s}$.

BKÜDB, 2019. Bitki Koruma Ürünleri Veri Tabanı. T.C. Tarım ve Orman Bakanlığı Gıda ve Kontrol Genel Müdürlüğü, https://bku.tarim.gov.tr (Erişim tarihi: 01.06.2019).

Bond, W., Davies, G., Turner, R. 2007. The biology and non-chemical control of Cleavers (Galium aparine L.). Henry Doubleday Research Association, Ryton Organic Gardens, Coventry, UK, https://www.gardenorganic.org.uk/sites/w ww.gardenorganic.org.uk/files/organicweeds/galium\%20aparine.pdf, (Erişim tarihi: 29.06.2019).

Bozkurt, M., Tursun, N. 2018. Muş ilinde buğday ürününe karışan yabancı ot tohumları. Turkish Journal of Weed Science, 21(2): 115.

Burton, N.R., Beckie, H.J., Willenborg, C.J., Shirtliffe, S.J., Schoenau, J.J., Johnson, E.N. 2017. Seed shatter of six economically important weed 
species in producer fields in Saskatchewan. Canadian Journal of Plant Science, 97(2): 266276.

$\mathrm{CABI}, 2019$. Datasheet Galium aparine (cleavers). Invasive Species Compendium, https://www.cabi.org/isc/datasheet/24772, (Erişim tarihi: 06.03.2019).

Christal, A. 2000. Intraspecific variation in seed dormancy and germination among populations of Stellaria media and Galium aparine. Doktora Tezi, University of Edinburgh, $358 \mathrm{p}$.

Christoffoleti, P.J., Caetano, R.S.X. 1998. Soil seed banks. Scientia Agricola, 55: 74-78.

Cirujeda, A., Aibar, J., Zaragoza, C. 2011. Remarkable changes of weed species in Spanish cereal fields from 1976 to 2007. Agronomy for Sustainable Development, 31: 675-688.

Davis, P.H., Mill, R.R., Tan, K. 1988. Flora of Turkey and the East Aegean Islands. Edinburgh University Press Vol: 10. Edinburgh, $590 \mathrm{p}$.

Deroo, A.C., Eckstein, P., Benaragama, D., Beattie, A.D., Willenborg, C.J. 2018. Evaluation of Galium species and populations using morphological characters and molecular markers. Weed Research, 59(1): 28-38.

Ehrendorfer, F., Schonbeck-Temesy, E. 1982. Galium L. "Alınmıştır: The Flora of Turkey and the East Aegean Islands, Volume 7. (ed) Davis, P.H., University of Edinburgh, Edinburgh, UK, 767-849 pp.

Gökalp, Ö., Üremiş, ì. 2015. Mardin buğday ekim alanlarında bulunan yabancı ot türlerinin, yaygınlıklarının ve yoğunluklarının belirlenmesi. Mustafa Kemal Üniversitesi Ziraat Fakültesi Dergisi, 20(1): 13-22.

Heap, I. 2019. International Survey of Herbicide Resistant Weeds. http://www.weedscience.org, (Erişim tarihi: 12.04.2019).

İnci, D., Galvin, L., Al-Khatib, K., Uludağ, A. 2019. Sumatran fleabane (Conyza sumatrensis) Resistance to glyphosate in peach orchards in Turkey. HortScience, 54(5): 873-879.

Kaya Altop, E.K., Mennan, H., Işık, D., Haghnama, K. 2017. Resistance to acetolactate synthase (ALS) inhibitors herbicides of Galium aparine L. (Catchweed bedstraw). Gaziosmanpaşa Üniversitesi Ziraat Fakültesi Dergisi, 34(3): 91-99.

Kolářová, M., Tyšer, L., Soukup, J. 2014. Weed vegetation of arable land in the Czech Republic: environmental a management factors determining weed species composition. Biologia, 69(4): 443-448.

LeBaron, H.M. 1982. Introduction. "Alınmıştır: Herbicide Resistance in Plants. (ed) LeBaron, H.M. and Gressel, J., John Wiley and Sons, 18.

Leeson, J.Y., Neeser, C., Kimmel, N., Vadnais, M. 2012. Alberta Weed Survey of Dryland Crops in 2010. Agriculture and Agri-Food Canada, Saskatoon Research Center, Saskatoon, Saskatchewan, $375 \mathrm{p}$.

Lundkvist, A., Verwijst, T. 2011. Weed Biology and Weed Management in Organic Farming. "Alınmıştır: Research in Organic Farming. (ed) Nokkoul, R., ISBN: 978-953-307-381-1, InTech, 157-186 pp, http://www.intechopen.com/books/researc h-in-organic-farming/weed-biology-andweed-management-inorganic-farming.

Mennan, H. 1998. Samsun İli Buğday Ekim Alanlarında Önemli Zararlara Neden Olan Kokarot (Bifora radians Bieb.) ve Yapışkanotu (Galium aparine L.)'nun Ekonomik Zarar Eşiklerinin ve Bazı Biyolojik Özelliklerinin Araştırılması. Doktora Tezi, Fen Bilimleri Enstitüsü, Çukurova Üniversitesi, $137 \mathrm{~s}$.

Mennan, H., Işık, D. 2003. Invasive weed species in onion production systems during the last 25 years in Amasya, Turkey. Pakistan Journal of Botany, 35(2): 155-160.

Mennan, H., Ngouajio, M. 2006. Seasonal cycles in germination and seedling emergence of summer and winter populations of catchweed bedstraw (Galium aparine) and wild mustard (Brassica kaber). Weed Science, 54: 114-120.

Mennan, H., Streibig, J.C., Ngouajio, M., Cankaya, S. 2011. Response of two catchweed bedstraw (Galium aparine) populations to postemergence herbicides in winter wheat. International Journal of Pest Management, 57(4): 347-356.

Milanova, S., Baeva, G., Nakova, R., Maneva, S., Chavdarov, L., Stoimenova, G., Velichkova, T. 2007. Some changes and trends in the weed communities in last years in Sofia region. 9th Symposium on Flora of Southeastern Serbia and Neighbouring Regions, 1-3 September, Serbia, 55-61 pp.

Nezahat Gökyiğit Botanik Bahçesi, 2019. Galium (Hızı arama). Türkiye Bitkileri Listesi, https://www.bizimbitkiler.org.tr/, (Erişim tarihi: 27.06.2019). 
Novak, R., Dancza, I., Szentey, L., Karaman, J. 2009. Arable Weeds of Hungary. The fifth National Weed Survey (2007-2008). Ministry of Agriculture and Rural development, Budapest, Hungary.

Özhatay, N. 2000. Galium L. "Alınmıştır: The Flora of Turkey and the East Aegean Islands, Volume 11 (Suppl.). (ed) Güner, A., Özhatay, N., Ekim, T. and, Baser, K.H.C., University of Edinburgh, Edinburgh, UK, 218-219 pp.

Royo-Esnal, A., Torra, J., Conesa, J.A., Recasens, J. 2010. Characterisation of emergence of autumn and spring cohorts of Galium spp. in winter cereals. Weed Research, 50: 572-585.

Ryan, G.F. 1970. Resistance of common groundsel to simazine and atrazine. Weed Science, 18: 614-616.

Saric, T., Ostojic, Z., Stefanovic, L., Milanova, S.D., Kazinczi, G., Tyser, L. 2011. The changes of the composition of weed flora in Southeastern and Central Europe as affected by cropping practices. Herbologia, 12(1): 527.

Seefeldt, S.S., Jensen, J.E., Fuerst, E.P. 1995. Loglogistic analysis of herbicide dose-response relationships. Weed Technology, 9: 218-227.

Shimono, Y., Konuma, A. 2007. Effects of humanmediated processes on weed species composition in internationally traded grain commodities. Weed Research, 48(1): 10-18.

Sırma, M., Kadıoğlu, İ., Güncan, A. 1997. Tokat ve yöresinde tohumluk buğdayda selektörden önce ve sonra ürüne karışan yabancı ot tohumlarının ve yoğunluklarının belirlenmesi. Türkiye II. Herboloji Kongresi, İzmir, s. 1-4.

Solak, H. 2007. Konya Yöresinde Yaygın Bazı Yabancı Ot Tohumlarının Çimlenme Özellikleri Üzerinde Araştırmalar. Yüksek Lisans Tezi, Fen Bilimleri Enstitüsü, Selçuk Üniversitesi, $124 \mathrm{~s}$.

Soylu, S., Sertkaya, E., Üremiş, I., Bozkurt, I.A., Kurt, Ş. 2017. Hatay ili marul (Lactuca sativa L.) ekim alanlarında görülen önemli hastalık etmenleri, zararlı ve yabancı ot türleri ve yaygınlık durumları. Mustafa Kemal Üniversitesi Ziraat Fakültesi Dergisi, 22(1): 23-33.

Şin, B., Kadıoğlu, i.., Kamışlı, B. 2016. Tokat ilinde buğday ürünü içerisine karışan yabancı ot tohumlarının belirlenmesi. Turkish Journal of Weed Science, 19(2): 28-37.
Taştan, B., Erçiş, A., Yıldııım, A. 1993. Yapışkanotu (Galium tricornutum Dandy)'nun biyolojik ve çıkış özellikleri üzerine araştırmalar. Bitki Koruma Bülteni, 33(1-2): 8-14.

Taylor, K. 1999. Galium aparine L. Journal of Ecology, 87: 713-730.

Tursun, N. 2012. Buğday ekim alanlarında görülen kısır yabani yulaf (Avena sterilis L.)'ın fenoxapropp-ethyl etkili maddeli herbisitlere karșı dayanıklıığının hızlı test yöntemi ile belirlenmesine yönelik araștırmalar. Tarım Bilimleri Araștırma Dergisi, 5(2): 161-166.

Ulber, L., Henning, S.H., Klimek, S. 2010. Using selective herbicides to manage beneficial and rare weed species in winter wheat. Journal of Plant Diseases and Protection, 117(5): 233239.

Uludağ, A. 1993. Diyarbakır ve Yöresinde Buğday, Mercimek Kültürlerindeki Önemli Yabancı Otların Dağılışı ve Bunların Biyolojik Özellikleri Üzerinde Araştırmalar. Yüksek Lisans Tezi, Cumhuriyet Üniversitesi, Fen Bilimleri Enstitüsü, Tokat, $50 \mathrm{~s}$.

Uludağ, A., Katkat, M. 1993. Güneydoğu Anadolu Bölgesinde meyve fidanlıklarında bulunan yabancı otlar ve yoğunluklarının belirlenmesi üzerine çalışmalar. Türkiye I. Herboloji Kongresi, 3-5 Şubat, Adana, s. 175-184.

Uludağ, A., Özer, Z. 1999. Farklı sıcaklıklarda bazı mekanik işlem ve kimyasal madde uygulamalarının boynuzotu (Cerastium dichotomum L.), boynuzlu yoğurtotu (Galium tricornutum Dandy.), Çobantarağı (Scandix pecten-veneris L.) ve yapışkanotu (Asperula arvensis L)'nun çimlenmeye etkisi. Türkiye Herboloji Dergisi, 2(1): 6-16.

Uludağ, A., Park, K., Mallory-Smith, C.A. 2005. Herbicide droplet test for detection of fenoxaprop resistance in wild oat. WSSA Abstract Book, 45: 19-20.

Uludağ, A., Nemli, Y., Rubin, B. 2006. Seed and seedlings assays for rapid detection of fenoxaprop resistance in sterile wild oat (Avena sterilis). Journal of Agriculture and Biological Sciences, 2: 149-153.

Uludag, A., Nemli, Y., Tal, A., Rubin, B. 2007. Fenoxaprop resistance in sterile wild oat (Avena sterilis) in wheat fields in Turkey. Crop Protection, 26(7): 930-935.

Uludağ, A. 2017. Konuralp Çeltiği Bağlamında Tarım, Çevre, Kültür, Medeniyet. 3üncü Uluslararası Düzce Tarih, Kültür ve Sanat Sempozyumu, 05-07 Mayıs, Düzce, s. 476-487. 
Uluğ, E., Kadıŏglu, ì., Üremiş, ì. 1993. Türkiye'nin Yabancıotları ve Bazı Özellikleri. T.C. Tarım ve Köy İşleri Bakanlığı, Zirai Mücadele Araştırma Enstitüsü Müdürlüğü, Yayın No: 78, Adana.

Üremiş, i. 2005. Determination of weed species and their frequency and density in olive grovers in Hatay Province of Turkey. Pakistan Journal of Biological Sciences, 8(1): 164-167.

Üremiş, i., Sertkaya, E., Sertkaya, G., Yıldırım, A.E. 2013. Hatay ili kayısı bahçelerinde bulunan yabancı ot türlerinin, yaygınlıklarının ve yoğunluklarının belirlenmesi. Mustafa Kemal Üniversitesi Ziraat Fakültesi Dergisi, 18(2): 47-54.

Van den Brand, W.G.M. 1984. Biologie en ecologie van kleefkruid (Galium aparine). Agricultural University in Wageningen, The Netherlands, $31 \mathrm{p}$.

Van der Weide, R.Y. 1993. Population dynamics and population control of Galium aparine L. Agricultural University in Wageningen, The Netherlands, 141 p.

Vrbnicanin, S., Kresovic, M., Bozic, D., Simic, A., Maletic, R., Uludağ, A. 2012. The effect of ryegrass (Lolium italicum L.) stand densities on its competitive interaction with cleavers (Galium aparine L.). Turkish Journal of Agriculture and Forestry, 36: 121-131.

Wilson, B.J., Wright, K.J. 1990. Predicting the growth and competitive effects of annual weeds in wheat. Weed Research, 30(3): 201-211.

Yang, Li-E., Meng, Y., Peng, De-L., Nie, Ze-L., Sun, H. 2018. Molecular phylogeny of Galium L. of the tribe Rubieae (Rubiaceae) - Emphasis on Chinese species and recognition of a new genus Pseudogalium. Molecular Phylogenetics and Evolution, 126: 221-232.

Yavuz, D.Ö. 2013. Buğday Ekim Alanlarında Sorun Olan Bazı Geniş Yapraklı Yabancı Otların Kimyasal Mücadelesinin Optimizasyonu. Doktora Tezi, Bitki Koruma Anabilim Dalı, Fen Bilimleri Enstitüsü, Adnan Menderes Üniversitesi, 156 s.

Yıldırım, A., Ekim, T. 2003. Orta Anadolu Bölgesi yabancı ot florası. Bitki Koruma Bülteni, 43(14): 1-98.

Zel, M. 1994. Güneydoğu ve Doğu Anadolu Bölgeleri hububat Tarlalarında Bulunan Yabancı Otların Dağııımı ve Ortalama Yoğunlukları. Araştırma Projesi Nihai Raporu, Türkiye Fitopatoloji Derneği Yayınları, Yayın No:8, İzmir, 137 s. 